\title{
Radiofrequency radiation at Stockholm Central Railway Station in Sweden and some medical aspects on public exposure to RF fields
}

\author{
LENNART HARDELL $^{1}$, TARMO KOPPEL ${ }^{2}$, MICHAEL CARLBERG $^{1}$, MIKKO AHONEN $^{3}$ and LENA HEDENDAHL $^{4}$ \\ ${ }^{1}$ Department of Oncology, Faculty of Medicine and Health, Örebro University, SE-701 82 Örebro, Sweden; \\ ${ }^{2}$ Department of Labour Environment and Safety Tallinn University of Technology, SCO351 Ehitajate tee 5, \\ 19086 Tallinn; ${ }^{3}$ Institute of Environmental Health and Safety, 11615 Tallinn, Estonia; \\ ${ }^{4}$ Independent Environment and Health Research Luleå, SE-972 53 Luleå, Sweden
}

Received June 5, 2016; Accepted July 27, 2016

DOI: $10.3892 /$ ijo.2016.3657

\begin{abstract}
The Stockholm Central Railway Station in Sweden was investigated for public radiofrequency (RF) radiation exposure. The exposimeter EME Spy 200 was used to collect the RF exposure data across the railway station. The exposimeter covers 20 different radiofrequency bands from 88 to $5,850 \mathrm{MHz}$. In total 1,669 data points were recorded. The median value for total exposure was $921 \mu \mathrm{W} / \mathrm{m}^{2}$ (or $\left.0.092 \mu \mathrm{W} / \mathrm{cm}^{2} ; 1 \mu \mathrm{W} / \mathrm{m}^{2}=0.0001 \mu \mathrm{W} / \mathrm{cm}^{2}\right)$ with some outliers over $95,544 \mu \mathrm{W} / \mathrm{m}^{2}$ (6 V/m, upper detection limit). The mean total RF radiation level varied between 2,817 to $4,891 \mu \mathrm{W} / \mathrm{m}^{2}$ for each walking round. High mean measurements were obtained for GSM + UMTS 900 downlink varying between 1,165 and $2,075 \mu \mathrm{W} / \mathrm{m}^{2}$. High levels were also obtained for UMTS 2100 downlink; 442 to $1,632 \mu \mathrm{W} / \mathrm{m}^{2}$. Also LTE 800 downlink, GSM 1800 downlink, and LTE 2600 downlink were in the higher range of measurements. Hot spots were identified, for example close to a wall mounted base station yielding over $95,544 \mu \mathrm{W} / \mathrm{m}^{2}$ and thus exceeding the exposimeter's detection limit. Almost all of the total measured levels were above the precautionary target level of $3-6 \mu \mathrm{W} / \mathrm{m}^{2}$ as proposed by the BioInitiative Working Group in 2012. That target level was one-tenth of the scientific benchmark providing a safety margin either for children, or chronic exposure conditions. We compare the levels of RF radiation exposures identified in the present study to published scientific results reporting adverse biological effects and health harm at levels equivalent to, or below those measured in this Stockholm Central Railway Station project. It should be noted that these RF radiation levels give transient exposure, since people are generally passing through the areas
\end{abstract}

Correspondence to: Dr Lennart Hardell, Department of Oncology, Faculty of Medicine and Health, Örebro University, SE-701 82 Örebro, Sweden

E-mail: lennart.hardell@regionorebrolan.se

Key words: electromagnetic fields, radiofrequency radiation, public exposure, base stations, exposimeter tested, except for subsets of people who are there for hours each day of work.

\section{Introduction}

On 31 May 2011 the WHO International Agency for Research on Cancer (IARC) categorized the radiation fields from mobile phones, and from other devices that emit similar non-ionizing electromagnetic field (EMF) radiation in the frequency range $30 \mathrm{kHz}$ to $300 \mathrm{GHz}$, as a Group 2B, i.e. a 'possible', human carcinogen $(1,2)$. Nine years earlier IARC had also classified the electromagnetic fields from overhead electric power lines as a Group 2B carcinogen (3).

The IARC decision on mobile phones was based mainly on two sets of case-control human studies: the Hardell group of studies from Sweden (4-6) and the IARC Interphone study (7-9). Both provided complementary and generally mutually supportive evidence of increased risk for brain tumours, i.e. glioma and acoustic neuroma. Later published studies by us (10-13) and the French CERENAT study on glioma and meningioma published in 2014 (14) supported an increased risk for brain tumours and use of mobile phones. These results were further supported by a study on mice showing tumourpromoting effect from radiofrequency $(\mathrm{RF})$ radiation at low to moderate levels $(0.04$ and $0.4 \mathrm{~W} / \mathrm{kg} \mathrm{SAR})$, radiation well below exposure limits for users of mobile phones (15). Thus, implications of the study by Tillman et al (16) were successfully tested. It should be added that a long-term animal toxicity study at $900 \mathrm{MHz}$ published in 1997 resulted in statistically significant increased lymphoma risk in mice (17).

Recently, a report was released from The National Toxicology Program (NTP) under the National Institutes of Health (NIH) in USA on the largest ever animal study on cell phone RF radiation and cancer (18). An increased incidence of glioma and malignant Schwannoma in the heart was found. Acoustic neuroma or vestibular Schwannoma is the same type of tumour as the one found in the heart, although benign.

The carcinogenicity findings evaluated by IARC in 2011 were related to personal wireless phone use, including mobile phones and DECT phones. The overall exposure including 
mobile phone base stations, radio- and TV-transmitters, DECT base stations and wireless local area networks (WLAN) is not very well known. Epidemiological studies of mobile phone base stations indicated health risks for humans, see a review of Khurana et al (19), but did not contain enough exposure information.

The exposure guideline by the International Commission on Non-Ionizing Radiation Protection (ICNIRP) was established in 1998 (20) and was based on thermal (heating) effects from RF radiation neglecting non-thermal biological effects. It was updated in 2009 (21) and stated that: 'it is the opinion of ICNIRP that the scientific literature published since the 1998 guidelines has provided no evidence of any adverse effects below the basic restrictions and does not necessitate an immediate revision of its guidance on limiting exposure to high frequency electromagnetic fields. Therefore, ICNIRP reconfirms the 1998 basic restrictions in the frequency range $100 \mathrm{kHz}$ to $300 \mathrm{GHz}$ until further notice'. The guideline provided by ICNIRP still recommends $10 \mathrm{~W} / \mathrm{m}^{2}$ as a reference level for limiting public's exposure to the RF-EMFs (2-300 GHz) (20).

It should be noted that the ICNIRP guideline, although only a recommendation, is nevertheless used in most European countries as well as in many other countries. The guideline is based on short-term (acute) exposures but not chronic, low-intensity cumulative exposures, nor possible health effects. ICNIRP safety limits do not acknowledge effects from long-term exposure and non-thermal biological effects from RF-EMF exposure. According to the philosophy document of ICNIRP (22): 'Some guidelines may still not provide adequate protection for certain sensitive individuals nor for normal individuals exposed concomitantly to other agents'. In practice this means, that if simultaneously exposed to chemicals and RF radiation $(15,16)$, the ICNIRP guideline does not protect. The philosophy document of ICNIRP (22) also states: 'Different groups in a population may have differences in their ability to tolerate a particular NIR (Non-Ionizing Radiation) exposure. For example, children, the elderly, and some chronically ill people might have a lower tolerance for one or more forms of NIR exposure than the rest of the population'. However, this is not considered in existing ICNIRP (1998) guideline document (20) and for example Gandhi et al (23) provide a historical overview how ICNIRP and the Federal Communications Commission (FCC) standard setting is based on (adult) military recruit head and body models, not children's.

ICNIRP's goal has been to harmonize guidelines worldwide and most countries have adopted the ICNIRP's guidelines into their national legislation. Using wireless internet access is compatible with ICNIRP's guidelines, but may exceed the BioInitiative Report recommendation (24). There is a vast body of literature that shows non-thermal adverse health effects from RF radiation. These, as well as thermal effects, have been evaluated in several reports, e.g. the BioInitiative report from 2007 (25) and in the 2012 update (26). The 2007 Bioinitiative report suggested a precautionary target level of $1,000 \mu \mathrm{W} / \mathrm{m}^{2}$ for outdoor pulsed $\mathrm{RF}$ radiation that could be applied to sources from cell tower antennas, Wi-Fi, WiMAX and other similar sources (25). The BioInitiative 2012 Report defined the scientific benchmark for possible risks as $30-60 \mu \mathrm{W} / \mathrm{m}^{2}$, based in part on post-2007 studies by
Thomas et al (27,28), Heinrich et al (29) and Buchner and Eger (30). Considering also chronic exposure and sensitivity among children the precautionary target level was proposed to one tenth of this, $3-6 \mu \mathrm{W} / \mathrm{m}^{2}$, see Chapter 24 of the BioInitiative Report (26). However, the studies by Thomas et al $(27,28)$ and Heinrich et al (29) used personal dosimetry without differentiating up-and downlink and without presenting actual measurements, but only percentages of the reference levels. Also shielding by the body may preclude any statement about actual exposure.

The BioInitiative report guideline obviously differs from the one proposed by ICNIRP, largely because ICNIRP protects only against acute, thermal injury while the BioInitiative recommendations address chronic exposures to non-thermal, low-intensity exposures for which mounting evidence shows adverse health effects. The ICNIRP level has been vigorously propagated by that organisation in order to harmonize guidelines worldwide. With few exceptions it has been a successful story and most countries have adopted the ICNIRP guideline. This gives a 'green card' to roll out the technology, for example using wireless internet access in schools (24), since the high exposure level by ICNIRP is rarely compromised.

There are few studies in this area on public exposure, other than for example outdoor exposure in urban and rural areas in Sweden (31), in a workplace (32), the metro in Warsaw (33) and a study with body-worn exposimeters in The Netherlands (34).

The aim of the present study was to assess RF radiation exposure in a public transportation hub, Stockholm Central Railway Station in Sweden. Many shops, restaurants and offices are located within this area. The Central Station contains many people, those working there and those commuting, thus, both short- and long-term exposure occurs. There is a lack of exposure studies in public places in Sweden. The previous measurement studies are outdated due to the rapid technology shift $(35,36)$. We selected a place visited by many persons that are exposed to RF radiation. This was a measurement study with no involvement of test persons. Thus, no ethical permission was needed. We discuss also some laboratory studies on RF-radiation that will help the reader to understand the context of the exposer logger measurements. Especially interesting are non-thermal levels of RF radiation and biological effects.

\section{Materials and methods}

EME Spy 200 exposimeter. In the present study an EME Spy 200 exposimeter with a valid calibration was used to collect the exposure data. The 20 predefined measured frequency bands are presented in Table I. They cover the frequencies of most public RF-EMF emitting devices currently used in Sweden. This band selective exposimeter covers 88 to $5,850 \mathrm{MHz}$. For FM, TV3, TETRA, TV4\&5, Wi-Fi and 5G the lower detection limit is $0.01 \mathrm{~V} / \mathrm{m}\left(0.27 \mu \mathrm{W} / \mathrm{m}^{2}\right)$; for all other exposures the lower detection limit is $0.005 \mathrm{~V} / \mathrm{m}\left(0.066 \mu \mathrm{W} / \mathrm{m}^{2}\right)$. The upper detection limit is $6 \mathrm{~V} / \mathrm{m}\left(95,544 \mu \mathrm{W} / \mathrm{m}^{2}\right)$. The sampling time used in this study was $4 \mathrm{sec}$ which is the fastest for the given exposimeter. The exposimeter measures different telecommunication protocols: FM (frequency modulation) radio broadcasting; TV (television) broadcasting; TETRA emergency services (police, rescue, etc.); GSM (global system for mobile communications) second generation mobile communications; UMTS (universal 
Table I. Predefined measurement frequency bands of EME Spy 200 exposimeter and frequency ranges.

\begin{tabular}{lrr}
\hline Frequency band & $\begin{array}{c}\text { Frequency } \\
\text { Min (MHz) }\end{array}$ & $\begin{array}{r}\text { Frequency } \\
\text { Max (MHz) }\end{array}$ \\
\hline FM & 87 & 107 \\
TV3 & 174 & 223 \\
TETRA I & 380 & 400 \\
TETRA II & 410 & 430 \\
TETRA III & 450 & 470 \\
TV4\&5 & 470 & 770 \\
LTE 800 (DL ${ }^{a}$ ), 4G & 791 & 821 \\
LTE 800 (UL ${ }^{b}$ ), 4G & 832 & 862 \\
GSM 900+ UMTS 900 (UL), 3G & 880 & 915 \\
GSM 900 + UMTS 900 (DL), 3G & 925 & 960 \\
GSM 1800 (UL) & 1,710 & 1,785 \\
GSM 1800 (DL) & 1,805 & 1,880 \\
DECT & 1,880 & 1,900 \\
UMTS 2100 (UL), 3G & 1,920 & 1,980 \\
UMTS 2100 (DL), 3G & 2,110 & 2,170 \\
Wi-Fi, 2G & 2,400 & $2,483.5$ \\
LTE 2600 (UL), 4G & 2,500 & 2,570 \\
LTE 2600 (DL), 4G & 2,620 & 2,690 \\
WiMax & 3,300 & 3,900 \\
Wi-Fi 5G & 5,150 & 5,850 \\
\hline
\end{tabular}

${ }^{\mathrm{a} D L}$, down link: transmission from base station to mobile phone; ${ }^{\mathrm{b}} \mathrm{UL}$, up link: transmission from mobile phone to base station.

mobile telecommunications systems) third generation mobile communications, 3G; LTE (long-term evolution) fourth generation mobile communications standard, 4G; DECT (digital European cordless telecommunications) cordless telephone systems standard; Wi-Fi wireless local area network protocol; WiMAX (worldwide interoperability for microwave access) wireless communication standard for high speed voice, data and internet.

EME SPY 200 is a sophisticated exposimeter, preferred by the majority of the EMF measurement's community. The unit utilizes 3-axis antennas to capture EMF radiation from all possible directions. The unit reports the exposure in a conservative manner since each reported value is the sampling outcome, where many samples are taken and statistically processed. The amount of the samples is dependent on the measurement band and could reach several hundreds. These samples are analyzed and minimum, mean, median and maximum values are calculated. For each band the sampling period is longer than the pulse length characteristic to that band and signal. This ensures that all the pulses are accounted for in the sampling period. The analysis method of EME SPY 200 allows differentiation of low and high wireless traffic, whereas the peak value might remain the same in both cases. Multiple antennas are of importance to reduce body shielding (37) as well as holding the exposimeter at some distance from the body.

Study design. The present study was performed during daytime November 7, (Saturday; 1 round), November 8 (Sunday; 3

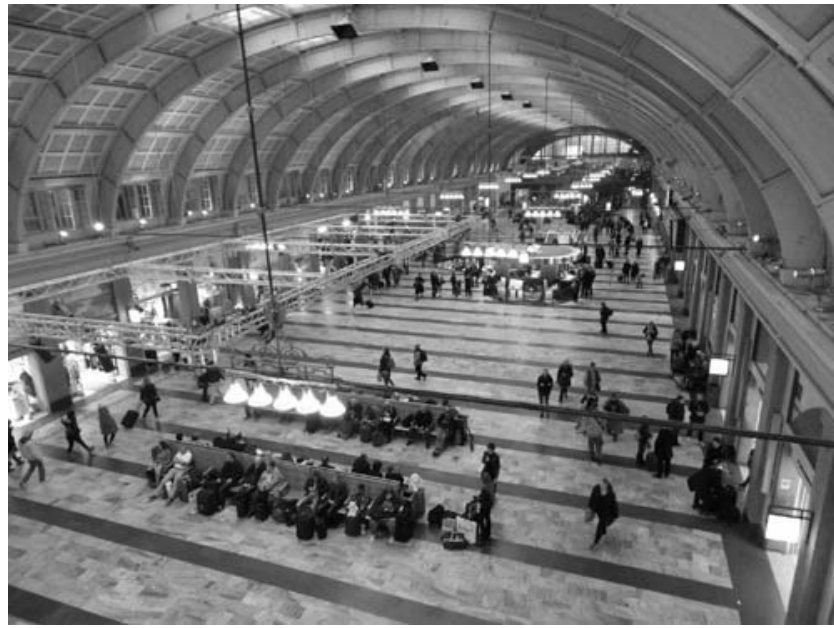

Figure 1. Stockholm Central Station main level (ground floor).

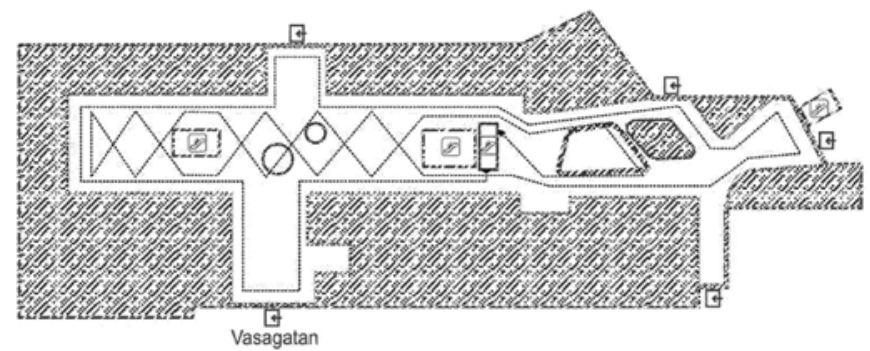

Figure 2. Stockholm Central Station ground floor measurement path.

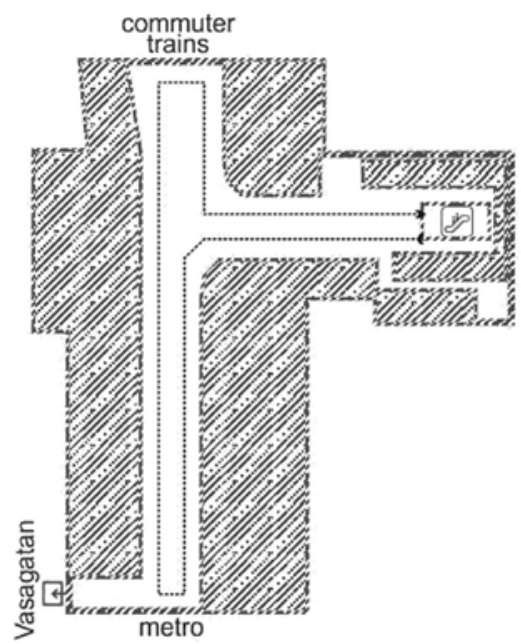

Figure 3. Stockholm Central Station lower level measurement path.

rounds) and November 9, 2015 (Monday; 3 rounds) at the Stockholm Central Station in Sweden. The upper level of the station is displayed in Fig. 1. To the left is the access to the street (Vasagatan) and to the right to commuter trains.

On each measurement round the main and lower floor were walked through with the exposimeter; the same path was always followed. The path was developed to make a clockwise tour of the station's main floor, followed by a zig-zag pattern across the main floor. Due to the narrow area of the lower floor, it was scanned only by a clockwise tour. The walking 
Table II. Mean values $\left(\mu \mathrm{W} / \mathrm{m}^{2}\right)$ for the seven measurement rounds.

\begin{tabular}{lccccccc}
\hline Date & $\begin{array}{c}151107 \\
\text { (Saturday) }\end{array}$ & $\begin{array}{c}151108 \\
\text { (Sunday) }\end{array}$ & $\begin{array}{c}151108 \\
\text { (Sunday) }\end{array}$ & $\begin{array}{c}151108 \\
\text { (Sunday) }\end{array}$ & $\begin{array}{c}151109 \\
\text { (Monday) }\end{array}$ & $\begin{array}{c}151109 \\
\text { (Monday) }\end{array}$ & $\begin{array}{c}151109 \\
\text { (Monday) }\end{array}$ \\
\hline Time (start) & $21: 18$ & $11: 00$ & $14: 45$ & $18: 50$ & $9: 45$ & $10: 50$ & $15: 50$ \\
No. of readings & 195 & 258 & 250 & 235 & 225 & 244 & 262 \\
FM & 5.8 & 9.6 & 6.7 & 78.0 & 10.1 & 2.0 & 50.1 \\
TV3 & 0.0 & 1.0 & 0.5 & 0.3 & 0.0 & 0.0 & 0.1 \\
TETRA I & 8.1 & 2.5 & 0.4 & 2.7 & 1.1 & 2.7 & 5.1 \\
TETRA II & 0.0 & 0.0 & 0.0 & 0.0 & 0.0 & 0.0 & 1.0 \\
TETRA III & 1.3 & 0.5 & 0.4 & 1.3 & 0.8 & 1.1 & 0.8 \\
TV4\&5 & 0.7 & 0.3 & 0.2 & 0.2 & 0.2 & 0.3 & 0.3 \\
LTE 800 (DL) & 556.8 & 472.9 & 421.3 & 482.9 & 250.1 & 363.6 & 864.4 \\
LTE 800 (UL $)$ & 0.1 & 0.7 & 0.6 & 0.1 & 0.3 & 0.1 & 0.1 \\
GSM+UMTS 900 (UL) & 5.4 & 4.1 & 4.3 & 14.3 & 8.0 & 4.8 & 4.1 \\
GSM+UMTS 900 (DL) & $1,561.6$ & $1,453.5$ & $1,409.5$ & $2,074.6$ & $1,337.0$ & $1,165.1$ & $1,314.0$ \\
GSM 1800 (UL) & 0.4 & 0.9 & 1.1 & 4.1 & 1.0 & 0.6 & 1.1 \\
GSM 1800 (DL) & 102.5 & 354.4 & 390.0 & 840.2 & 495.5 & 370.5 & 344.8 \\
DECT & 20.8 & 8.6 & 19.6 & 11.2 & 8.5 & 12.0 & 35.4 \\
UMTS 2100 (UL) & 0.0 & 0.1 & 0.5 & 0.3 & 0.5 & 0.1 & 0.2 \\
UMTS 2100 (DL) & 864.3 & 964.2 & $1,631.9$ & 893.3 & 441.5 & 557.1 & $1,239.6$ \\
Wi-Fi 2G & 1.6 & 0.9 & 1.2 & 2.6 & 1.2 & 1.9 & 2.0 \\
LTE 2600 (UL) & 0.1 & 0.1 & 0.1 & 0.2 & 0.1 & 0.1 & 0.1 \\
LTE 2600 (DL) & 404.7 & 309.3 & 674.5 & 483.3 & 372.4 & 331.0 & 683.6 \\
WiMax & 0.0 & 0.0 & 0.0 & 0.0 & 0.0 & 0.0 & 0.0 \\
Wi-Fi 5G & 0.7 & 0.9 & 1.5 & 1.6 & 1.7 & 3.9 & 1.4 \\
Total & $3,535.0$ & $3,584.4$ & $4,564.2$ & $4,891.2$ & $2,929.9$ & $2,817.0$ & $4,548.1$ \\
\hline
\end{tabular}

${ }^{a} \mathrm{DL}$, down link: transmission from base station to mobile phone; ${ }^{b} \mathrm{UL}$, up link: transmission from mobile phone to base station.

path is schematically shown in Figs. 2 and 3. The lower level contains businesses and access to the metro, commuter trains and Vasagatan; the main floor has also businesses, access to the trains and exits to the street.

In order to minimize the body's shielding effect to the exposimeter, the unit was held ahead within $\sim 0.4 \mathrm{~m}$ from the investigator's body.

Statistical methods. Means in $\mu \mathrm{W} / \mathrm{m}^{2}$ were calculated for all measured frequency bands and a box plot was constructed to illustrate the distribution of total exposure for all measurement rounds. Values at lower detection limit were treated as no (0) exposure. Total exposure was calculated as the sum of all measured frequency bands. Stata/SE 12.1 (Stata/SE 12.1 for Windows; StataCorp., College Station, TX, USA) was used for all calculations.

\section{Results}

In total 1,669 readings were collected varying from 195 to 262 during each round (median 244). Thus, the time varied between 13.0 and $17.5 \mathrm{~min}$ for different rounds.

The results for each round are displayed in Table II, and for all rounds in Table III. The mean total exposure level varied between 2,817 to $4,891 \mu \mathrm{W} / \mathrm{m}^{2}$ (or 0.28 to $0.49 \mu \mathrm{W} / \mathrm{cm}^{2}$; $1 \mu \mathrm{W} / \mathrm{m}^{2}=0.0001 \mu \mathrm{W} / \mathrm{cm}^{2}$ ) and the median value for total

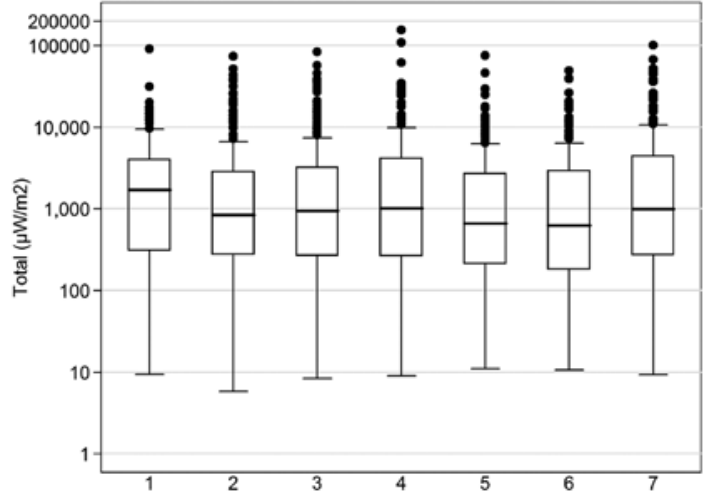

Figure 4. Box plot for total exposure in $\mu \mathrm{W} / \mathrm{m}^{2}$ for the seven measurement rounds. The median is indicated by a black line inside each box; the bottom and top of the boxes show first and third quartiles; the end of the whiskers are calculated as $1.5 x I Q R$ (interquartile range). Points represent outliers.

exposure (all measurement rounds) was $921 \mu \mathrm{W} / \mathrm{m}^{2}$. High mean measurements were obtained for GSM and UMTS 900 downlink varying between 1,165 and 2,075 $\mu \mathrm{W} / \mathrm{m}^{2}$. High mean levels were also obtained for UMTS 2100 downlink; 442 to $1,632 \mu \mathrm{W} / \mathrm{m}^{2}$. Also LTE 800 downlink, GSM 1800 downlink, and LTE 2600 downlink were in the higher range of measurements. Notably lower mean levels were seen for DECT varying between 8.5 to $35.4 \mu \mathrm{W} / \mathrm{m}^{2}$. The mean level results for FM 
Table III. Mean, median, minimum and maximum values $\left(\mu \mathrm{W} / \mathrm{m}^{2}\right)$ for all measurement rounds $(\mathrm{n}=1,669$ measurement points).

\begin{tabular}{|c|c|c|c|c|}
\hline Frequency band & Mean & Median & Min & Max \\
\hline FM & 23.7 & 0.0 & 0.0 & $9,206.3$ \\
\hline TV3 & 0.3 & 0.0 & 0.0 & 176.6 \\
\hline TETRA I & 3.1 & 0.0 & 0.0 & 834.8 \\
\hline TETRA II & 0.2 & 0.0 & 0.0 & 78.5 \\
\hline TETRA III & 0.9 & 0.0 & 0.0 & 100.9 \\
\hline TV4\&5 & 0.3 & 0.0 & 0.0 & 41.4 \\
\hline LTE $800\left(\mathrm{DL}^{\mathrm{a}}\right)$ & 491.8 & 55.8 & 0.0 & $41,281.2$ \\
\hline LTE $800\left(\mathrm{UL}^{\mathrm{b}}\right)$ & 0.3 & 0.0 & 0.0 & 142.8 \\
\hline GSM+UMTS 900 (UL) & 6.3 & 0.6 & 0.0 & 561.3 \\
\hline GSM+UMTS 900 (DL) & $1,467.2$ & 254.9 & 0.0 & $95,522.5$ \\
\hline GSM 1800 (UL) & 1.3 & 0.1 & 0.0 & 243.5 \\
\hline GSM 1800 (DL) & 418.6 & 22.9 & 0.0 & $58,843.8$ \\
\hline DECT & 16.7 & 0.3 & 0.0 & $3,637.2$ \\
\hline UMTS 2100 (UL) & 0.2 & 0.0 & 0.0 & 94.8 \\
\hline UMTS 2100 (DL) & 955.8 & 127.2 & 0.9 & $59,847.5$ \\
\hline Wi-Fi 2G & 1.6 & 0.2 & 0.0 & 186.3 \\
\hline LTE 2600 (UL) & 0.1 & 0.0 & 0.0 & 13.4 \\
\hline LTE 2600 (DL) & 470.1 & 64.6 & 0.0 & $40,158.8$ \\
\hline WiMax & 0.0 & 0.0 & 0.0 & 1.3 \\
\hline Wi-Fi 5G & 1.7 & 0.4 & 0.0 & 301.2 \\
\hline Total & $3,860.2$ & 920.6 & 5.8 & $155,263.4$ \\
\hline
\end{tabular}

${ }^{a} \mathrm{DL}$, down link: transmission from base station to mobile phone; ${ }^{b} \mathrm{UL}$, up link: transmission from mobile phone to base station.

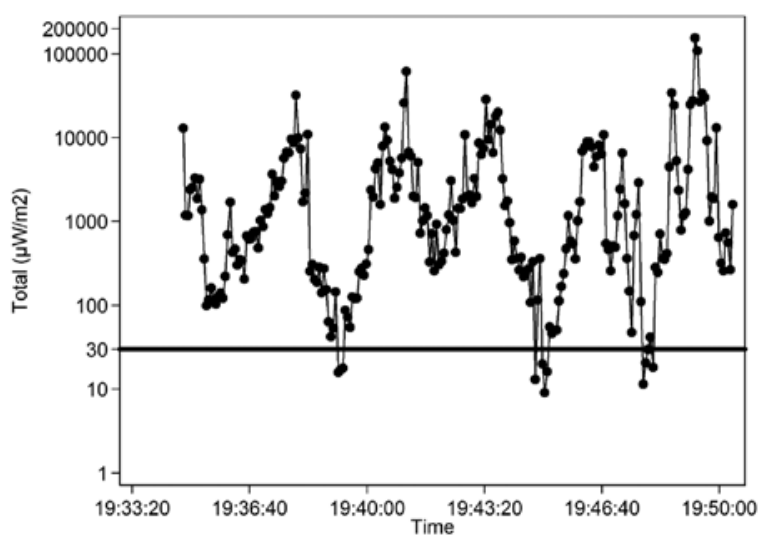

Figure 5. Total radiofrequency field exposure $\left(\mu \mathrm{W} / \mathrm{m}^{2}\right)$ of the highest exposure round $\left(151108,18: 50\right.$; mean exposure $\left.4,891.2 \mu \mathrm{W} / \mathrm{m}^{2}\right)$ by walking across the station. The horizontal line represents the exposure limit of $30 \mu \mathrm{W} / \mathrm{m}^{2}$ suggested by the BioInitiative Report (29).

radio varied between 2.0 to $78.0 \mu \mathrm{W} / \mathrm{m}^{2}$. Some of the results showed $0.0 \mu \mathrm{W} / \mathrm{m}^{2}$ since readings registered as lower detection limit were considered as 0 in the analysis.

In Fig. 4 the box plot shows total exposure in $\mu \mathrm{W} / \mathrm{m}^{2}$ for the seven measurement rounds. The overall median value was $921 \mu \mathrm{W} / \mathrm{m}^{2}$ with some outliers of $>150,000 \mu \mathrm{W} / \mathrm{m}^{2}$. Fig. 5 displays the variation over time for the highest exposure round.

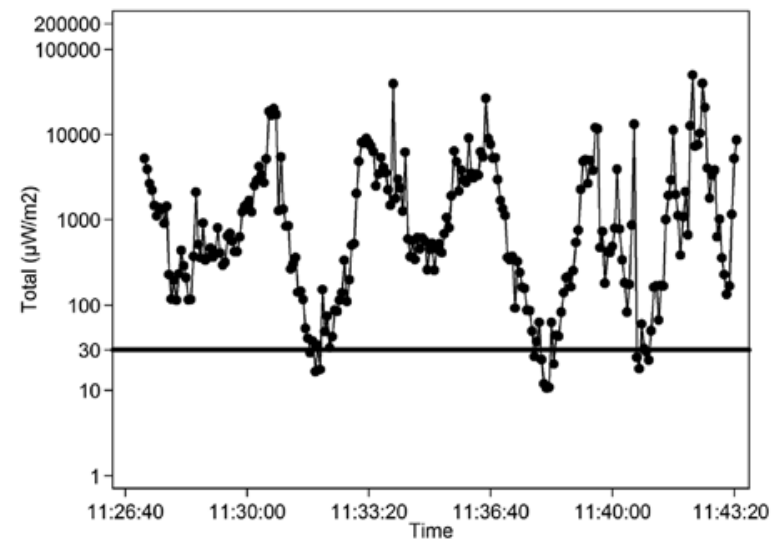

Figure 6. Total radiofrequency field exposure $\left(\mu \mathrm{W} / \mathrm{m}^{2}\right)$ of the lowest exposure round $\left(151109,10: 50\right.$; mean exposure $\left.2,817.0 \mu \mathrm{W} / \mathrm{m}^{2}\right)$ by walking across the station. The horizontal line represents the exposure limit of $30 \mu \mathrm{W} / \mathrm{m}^{2}$ suggested by the BioInitiative Report (29).

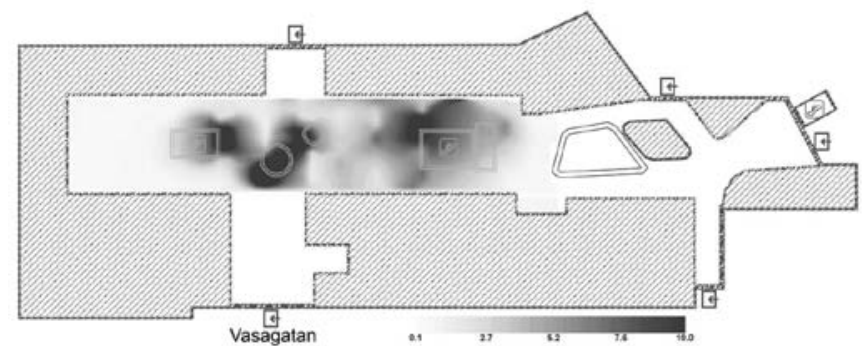

Figure 7. Stockholm Central Station ground floor with total field intensity map $(151108,19: 20)$ scale in $\mathrm{mW} / \mathrm{m}^{2}$.

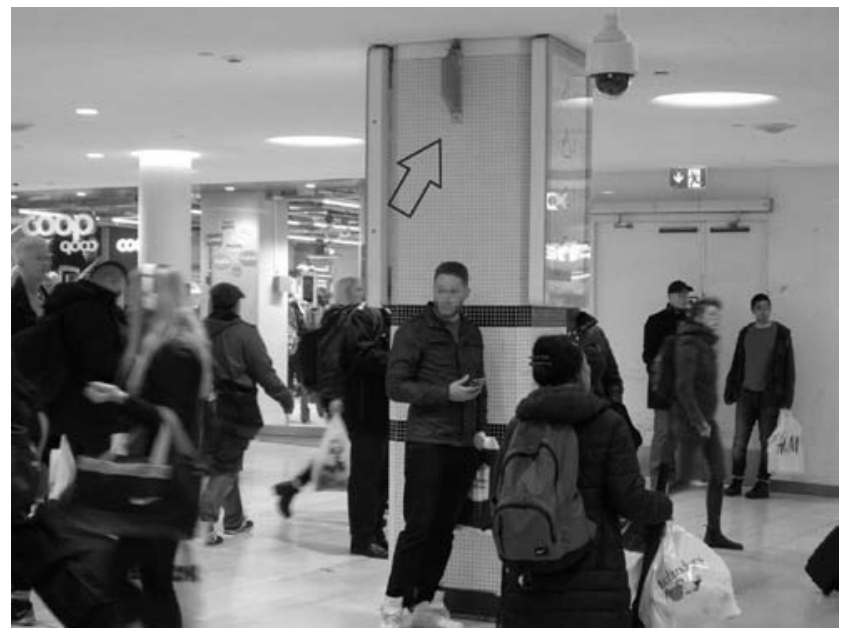

Figure 8. An example of highest exposure area. A man is standing with his smartphone just a couple of meters below a base station (see arrow). In that area maximum measured power density in the GSM +UMTS 900 downlink band was $95,544 \mu \mathrm{W} / \mathrm{m}^{2}$, which is the upper limit of measurement for EME Spy 200.

It should be noted that most measurements were $>100 \mu \mathrm{W} / \mathrm{m}^{2}$. In Fig. 6 similar results as in Fig. 5 are shown for lowest exposure round.

Fig. 7 shows total field intensity map on the Central Station main level. Clearly there were several hot spots, for example at 
places where people use to sit or stand waiting for their train or meeting with other persons.

One example of highest exposure area is shown in Fig. 8. In that area maximum measured power density in the GSM + UMTS 900 downlink band was $95,544 \mu \mathrm{W} / \mathrm{m}^{2}$, which is the upper limit of measurement in each frequency band for EME Spy 200. Note that the photo was not taken simultaneously with the measurement rounds.

\section{Discussion}

EME Spy 200 is a band specific exposimeter and gives the possibility to identify and measure most RF radiation bands currently used in Sweden. We selected Stockholm Central Station in Sweden since it is a place for communication with lots of daily visiting persons. It may be persons that transfer between the metro and train (or opposite), but also people that meet each other or are waiting during a considerable time for a transfer train. There are also lots of shops in that area with employees. We did not make any measurements in shops since the aim was to restrict the study to transfer areas. Anyhow, there is a possibility for many persons to be exposed to high $\mathrm{RF}$ radiation for shorter or longer time periods.

Major results. The major finding of the present study was that total $\mathrm{RF}$ radiation mean exposure for a walking round, see Figs. 2 and 3, varied between 2,817 to $4,891 \mu \mathrm{W} / \mathrm{m}^{2}$. GSM and UMTS 900 downlink contributed to most of the radiation dose. In fact, this together with UMTS 2100 downlink contributed to almost half of total exposure. Other major sources were LTE 800 downlink, GSM 1800 downlink and LTE 2600 downlink. Other sources were comparatively low. According to Table II, the vast majority of the mobile telephone exposure is from the downlink bands, i.e. the sources are the base station antennas placed around the railway station. Exposure from uplink levels was an insignificant percentage of the downlink exposure: LTE 800 0.06\%, GSM 900 0.44\%, GSM 1800 0.32\%, UMTS $21000.03 \%$ and LTE $26000.21 \%$.

All measured mean and median levels were well below ICNIRP's exposure guidelines at $2-10 \mathrm{~W} / \mathrm{m}^{2}$ (see below), but most of the measured levels were above the scientific benchmark of $30-60 \mu \mathrm{W} / \mathrm{m}^{2}$ as proposed by the BioInitiative Report (26). Obviously few total measurements were below $30 \mu \mathrm{W} / \mathrm{m}^{2}$, see Figs. 5 and 6.

There were also some hot spots for exposure. This is exemplified in Fig. 8 with a man standing close to a base station on the wall just below the roof. The measured exposure was $95,544 \mu \mathrm{W} / \mathrm{m}^{2}$, which is the upper detection limit for each frequency band for the exposimeter. Thus, it was not possible to get the exact value. People in general are not aware of this kind of exposure that may be considerable. Moreover, this is an example of an inappropriate placement of a base station with high downlink exposure. Note that the photo was taken separate from measurement rounds.

The exposure guidelines by ICNIRP. The reference values for radiofrequency electromagnetic fields were recommended in 1998 by ICNIRP to $2-10 \mathrm{~W} / \mathrm{m}^{2}$ for frequencies between $10 \mathrm{MHz}$ to $300 \mathrm{GHz}$. Up to $400 \mathrm{MHz}$ the recommendation is $2 \mathrm{~W} / \mathrm{m}^{2}$. The formula: frequency $/\left(2 \times 10^{8}\right)$ is used for frequen- cies between 400 and 2,000 MHz. Above 2,000 MHz up to $300 \mathrm{GHz}$ the recommended reference value is $10 \mathrm{~W} / \mathrm{m}^{2}(20)$.

The basic restrictions for time varying electric and magnetic fields for frequencies from $10 \mathrm{MHz}$ up to $10 \mathrm{GHz}$ for the specific energy absorption rate (SAR) is over $10 \mathrm{~g}$ of tissue for whole-body average set to $80 \mathrm{~mW} / \mathrm{kg}$, for localized head and trunk $2 \mathrm{~W} / \mathrm{kg}$ and for localized limbs $4 \mathrm{~W} / \mathrm{kg}$. FCC/Institute of Electrical and Electronics Engineers (IEEE) public safety limits use a $1 \mathrm{~g}$ rather than $10 \mathrm{~g}$ volume of tissue and the SAR limit for ICNIRP is $2 \mathrm{~W} / \mathrm{kg}$ in comparison to the FCC/IEEE 1.6 W/Kg SAR allowance.

These reference values and basic restrictions protect against injuries caused by a heating effect over $1^{\circ} \mathrm{C}$ after an exposure of $30 \mathrm{~min}$, and with a safety factor of 50 for general public (20). Injuries caused by other biological mechanisms than heating or from chronic effects are not considered in the above mentioned limit values.

Limitations due to method of measurements. The present study describes measurements mostly from far-field RF radiation. It describes the exposure that the citizen may be exposed to without himself/herself using personal wireless devices. Near-field exposure from people's own mobile phones held near the ear or in the hand when surfing on the internet may be a considerable contribution to the individual's total exposure.

We measured during seven rounds during three days yielding 1,669 readings in total. The exposure levels did somewhat vary between the different walking rounds but did not exceed 2-fold. However, the data does not show that either weekends or weekdays would exhibit higher exposure level. Many people pass through the station in rush hours, but also in weekends when traveling away and into the city. It should be noted that this is a conservative estimate of exposure. The results do not reflect personal wireless devices being carried around or used by individuals, just the 'ambient' RF levels of people not using devices.

The present study used an exposimeter for measurements. Because samples were taken every $4 \mathrm{sec}$, technologies with large differences between average and peak might not have been exactly evaluated, an inherent limitation of the exposimeter. For example the DECT-base stations and Wi-Fi router exposures may have been undervalued with the used exposimeter. Generally, peak signal level measurement data is interesting when discussing the non-thermal effects of radiofrequency radiation.

The shielding effect from the body of a person carrying an exposimeter can be considerable as shown by Bolte et al (38) when comparing a body worn exposimeter with an exposimeter mounted on a car roof. This was partly compensated in the present study by holding the exposimeter at some distance from the body. Bhatt et al (37) concluded that using an exposimeter with three antennas, as in the present study, may minimize body shielding.

Laboratory studies and medical aspects. The mean measurements in the Stockholm Central Station showed a total RF radiation between 2,817 to $4,891 \mu \mathrm{W} / \mathrm{m}^{2}$. Studies with laboratory animals exposed to RF radiation at or below these levels have shown influence on several physiological parameters in 
the body of mammals. Influence on the blood-brain barrier, proteins and microRNA in the brain, testicular function, oxidative stress in the cells and DNA damage have been shown. Also neurotransmitters in people living in a village were changed after activation of a GSM mobile phone base station. These are non-thermal effects and are discussed briefly in the following.

The blood brain barrier (BBB) may open by exposure to RF radiation and lead to leakage into the brain of large molecules, like albumin and different toxins. As a result of opening of the protective $\mathrm{BBB}$ layer that separates the brain from the blood, this pathological leakage of the $\mathrm{BBB}$ has been shown to be toxic to brain tissues and can cause damage to, and death of neurons $(39,40)$. Condensed dark neurons in the rats' brains are a sign of damage, and have been seen after $2 \mathrm{~h}$ of exposure to a GSM mobile phone both at 28 and 50 days after exposure $(39,40)$. Several studies on rats have shown opened BBB after RF radiation from a GSM mobile phone with peak power output down to $1,000 \mu \mathrm{W}$ and with an average whole body SAR-value down to $120 \mu \mathrm{W} / \mathrm{kg}$ (41). A U-shaped response curve has also been seen with stronger health effects by RF radiation at lower exposure levels than at higher exposure $(39,41)$.

Difference between genders after exposure to $\mathrm{RF}$ radiation has been found, where male rats got an increased BBB permeability for both GSM 900 and 1,800 MHz pulsed modulated $\mathrm{RF}$ radiation while female rats only got increased BBB permeability for the $900 \mathrm{MHz}$ frequency (42).

The hippocampus is a center for memory and learning in the brain, and in particular appears to be a primary target for neuronal damage from RF radiation and opened BBB. Exposure to $900 \mathrm{MHz} \mathrm{RF}$ radiation during $3 \mathrm{~h}$ per day for 28 days showed extravasation of albumin in the hippocampus and cortex and impaired spatial memory in exposed rats (43). Also exposure for $2 \mathrm{~h}$ per day for 55 weeks showed impaired memory in GSM $900 \mathrm{MHz}$ exposed rats, but no statistically significant alterations of histopathological parameters $(44,45)$.

$\mathrm{RF}$ radiation has been shown to increase protein synthesis in proliferating human cells after $8 \mathrm{~h}$ of exposure, but not in quiescent white blood cells. This indicates a higher sensitivity of growing organisms (46). Also the capacity to repair DNA double-strand breaks was more effected by RF radiation in stem cells compared to differentiated cells like fibroblasts (47).

In a long-term study mice were exposed to a GSM $900 \mathrm{MHz}$ mobile phone at SAR-level $370,000 \mu \mathrm{W} / \mathrm{kg}$ for $3 \mathrm{~h}$ a day or to a DECT base station at a SAR-level of $12,000-28,000 \mu \mathrm{W} / \mathrm{kg}$ for $8 \mathrm{~h}$ a day. After 8 months of exposure the two exposed groups of mice were compared with a sham exposed control group regarding 432 proteins from the cerebellum, hippocampus and frontal lobes of the brains. Comparative proteomics analyses revealed that 143 of the proteins had a statistically significant downregulation or an overexpression. Several neural function related proteins, like apolipoprotein $\mathrm{E}$, heat shock proteins and cytoskeletal proteins as well as proteins of the brain metabolism were altered (48).

In two long-term studies rats were exposed to $\mathrm{RF}$ radiation emitted from a Wi-Fi system of $2.4 \mathrm{GHz}$ for $24 \mathrm{~h}$ a day for 12 months. The peak power from the $\mathrm{Wi}-\mathrm{Fi}$ was $100,000 \mu \mathrm{W}$ with the antenna $50 \mathrm{~cm}$ above the cage. The SAR value over $10 \mathrm{~g}$ of brain tissue was $1,030 \mu \mathrm{W} / \mathrm{kg}$. In one of the studies
micro-RNAs (miRNA) in the rat brains were examined. Two of the five examined miRNA, 107 and 106b-5p, decreased 3.3 and 3.6 times, respectively. miRNA plays an important role in the proliferation, differentiation, function and maintenance of neuronal cells. Dysfunction of miRNA pathways may be a potential contribution to pathogenesis of neurodegenerative disorders and also a key indicator of epigenetic changes and cancer risk (49).

In the other study the rat testes and prostate were examined. The SAR value in the exposed rat testes and prostate was $1,020 \mu \mathrm{W} / \mathrm{kg}$ over 10 gram tissue. Compared to the sham exposed rats the Wi-Fi exposed rats showed statistically significant more head defects of the sperms and effects on testicular function and histology (50). Other Wi-Fi exposure studies have indicated damage to DNA in sperms (51-53).

Yakymenko et al (54) showed in a review of 100 studies investigating oxidative effects of low-intensity $\mathrm{RF}$ radiation in living cells, that exposure down to $2,500 \mu \mathrm{W} / \mathrm{m}^{2}(55)$ and with SAR values down to $600 \mu \mathrm{W} / \mathrm{kg}(56,57)$ could increase oxidative stress in the cells. Long-term RF radiation exposure at the frequencies $900,1,800$ and $2,450 \mathrm{MHz}$ for $2 \mathrm{~h}$ per day 5 days per week for 30-180 days at SAR 595-667 $\mu \mathrm{W} / \mathrm{kg}$ have shown induced oxidative stress, reduced levels of neurotransmitters and downregulation of mRNA, increase in pro-inflammatory cytokines and DNA damage with single strand breaks in the hippocampus in the brain in the exposed rats (57-59). Cognitive impairments in learning and memory were also shown (59). Increase in frequency seems to have more deleterious effect on several of the parameters; 1,800 and $2,450 \mathrm{MHz}$ had a statistically significant effect not only compared to sham exposed animals but also in some cases compared to $900 \mathrm{MHz}$ exposure.

Even lower exposure levels in rats, down to SAR $85 \mu \mathrm{W} / \mathrm{kg}$, for $900 \mathrm{MHz}$ during $2 \mathrm{~h} /$ day, 5 days/week for 30 days showed increase in oxidative stress parameters in lipid peroxidation and protein oxidation. Also cognitive function showed a statistically significant impairment in spatial memory in the rats (60).

Buchner and Eger (30) performed a study with 60 participants out of the 2,000 inhabitants, who lived in the village Rimbach in Germany, when a GSM mobile base station was built in the spring of 2004. The neurotransmitters adrenaline, noradrenaline, dopamine and phenyletylamine (PEA) were measured in second morning urine samples before the base station was activated and 6, 12 and 18 months after. The RF radiation was measured outside each participant's house in peak value of the power density after the activation of the base station. The 60 study participants were divided into three exposure groups, $<60,60-100$ and $>100 \mu \mathrm{W} / \mathrm{m}^{2}$.

After the activation of the GSM base station the levels of the stress hormones adrenaline and noradrenaline showed a statistically significant increase during the first six months and then decreased but were not restored to initial level after 18 months. This was seen especially for the children and the chronically ill adults. A statistically significant decrease was seen for dopamine levels during the first six months $(\mathrm{P}<0.0002)$, then dopamine levels increased but were not restored to the initial level. These three neurotransmitters showed a dose-response relationship with highest influence for the participants with exposure $>100 \mu \mathrm{W} / \mathrm{m}^{2}$ at home. PEA levels decreased for the 
highest exposed group first, but after 18 months all three exposure groups had a statistically significant decrease $(\mathrm{P}<0.0001)$. Wireless devices like DECT, Wi-Fi and bluetooth at home seemed to amplify the effect of GSM radiation. Even the lowest exposed group, $<60 \mu \mathrm{W} / \mathrm{m}^{2}$, had decreased dopamine and PEA levels after 18 months. Chronic dysregulation of the catecholamine system and PEA may contribute to health problems and chronic illnesses (30).

The NTP animal study (18) confirms findings in epidemiological studies of an increased risk for glioma and acoustic neuroma among people that use wireless phones, both mobile phones and cordless phones (DECT). In 2013, accumulating evidence from brain cancer studies resulted in a recommendation to upgrade IARC's 2011 classification of RF from a Group 2B - Possible Human Carcinogen to Group 1 - Known Carcinogen (61). The NTP study has greatly strengthened the evidence of risk, and reaffirms that it is sufficient to reclassify wireless phone radiation as a known cancer causing agent, and confirms the inadequacy of existing public safety limits.

Environmental $R F$ radiation exposure. There are no other published studies in Sweden on RF radiation exposure in public places like this one at the Stockholm Central Station. The study by Hamnerius et al (35) from 2000 has merit as an RF radiation baseline, and may establish how much exposure has changed over time. Estenberg and Augustsson (31) measured with a car-mounted device the frequency range $30-3,000 \mathrm{MHz}$ in some public places; rural, urban and city. The arithmetic mean measured exposure was in Stockholm city $6,700 \mu \mathrm{W} / \mathrm{m}^{2}$, in urban areas (4 towns) $1,500 \mu \mathrm{W} / \mathrm{m}^{2}$, and in rural areas (2 places) $230 \mu \mathrm{W} / \mathrm{m}^{2}$. Similarly as in present study the major sources were GSM and UMTS downlinks.

Within one year, from 2011 to 2012, total RF radiation levels in all studied European outdoor city areas in combination increased by $57.1 \%$ (62). Over the past decade or so, RF radiation levels have significantly increased in our environment. Frei et al (63) estimated that the introduction of mobile phone technology has resulted in a 10 -fold increase of RF radiation at outdoor areas compared to the time period before when broadcast transmitting was the most relevant source. Urbinello et al (62) measured 3 European cities, including train stations. The RF radiation measurement values in train stations ranged from $0.32\left(272 \mu \mathrm{W} / \mathrm{m}^{2}\right)$ to $0.57 \mathrm{~V} / \mathrm{m}$ $\left(862 \mu \mathrm{W} / \mathrm{m}^{2}\right)$. Authors comment: 'Interestingly, across all indoor areas in all cities, mobile phone base station exposure showed a stronger temporal increase than mobile phone handset exposure' (62).

In a study by Bolte et al (64) 98 persons in The Netherlands carried a body-worn EME-Spy 121 for $24 \mathrm{~h}$. Passing time at a railway station or going by train and metro showed high exposure, mean power density 304-354 $\mu \mathrm{W} / \mathrm{m}^{2}$, although visiting pubs or cafés showed even higher exposure, mean $526 \mu \mathrm{W} / \mathrm{m}^{2}$. These are places where many people gather together and use mobile phones and laptops. During 2010 and 2011 when the study was done exposure from UMTS, both downlink and uplink, was low and few owned and used smartphones.

Grytz and Karpowicz (33) measured RF radiation inside the metro in Warsaw. The major source of exposure was the 900 GSM system. In another publication the mean exposure based on 173,323 measurements in 23 countries worldwide was reported to be $730 \mu \mathrm{W} / \mathrm{m}^{2}$ (65). However, these measurements covered a different time period and not the same frequency range as in this study. Furthermore, the study methods were not clearly described. Markakis and Samaras (66) made a measurement campaign in Greece from 2010 to 2012 and concluded that signals from mobile base stations were dominant in workplaces and schools, whereas in home environment the dominant exposure was from wireless phones and computer networks. Viel et al (67) used exposimeters to investigate the participants' exposure budget across the week. They concluded the highest exposure to reside during Sundays, with main contributions from UMTS Tx (transmitting, upload) and DECT.

The present study is unique and different from those published previously since it covers 20 different frequency bands including most currently used frequency bands. Thus, in addition to the changing technology, our results are not comparable with previous ones such as the one from 2010 by Joseph et al (68) or even the results by Tell and Kavet (69) from 2014 stating that the FM band was a major contributor to overall power density. These results are less reliable comparing with our findings. Mean values for the FM band was orders of magnitude lower than e.g. for GSM+UMTS 900 (DL) and UMTS 2100 (DL) in this study, see Table II.

In conclusion, the aim of the present study was to assess the exposure to RF radiation in a public place in Sweden visited daily by many persons. We compare our results with nonthermal effects in laboratory investigations and also discuss results in animal studies on the carcinogenic risk. In epidemiological studies an increased risk of glioma and acoustic neuroma has been found in persons exposed to RF radiation from wireless phones. In animal studies RF radiation has been shown to promote tumours but also cause glioma and acoustic neuroma. There are also by now mechanistic studies such as oxidative effects from low-intensity RF radiation. We call for upgrading the carcinogenic potential to IARC Group 1, the agent causes cancer in humans.

In this study, real-time band specific exposure measurements at a public place showed comparatively high exposure from all mobile telephone and networking bands. The highest contributors to the exposure were download frequencies from the base stations at GSM+UMTS 900, UMTS 2100, LTE800, LTE 2600 and GSM 1800 bands. However, these RF exposure levels in this study are transient, since people are generally passing through the areas tested, except for subsets of people, i.e., security and police staff, cafe workers, shop workers, janitors, information counter people, who are there for hours each day of work.

Due to the rapid development of the telecommunications technology and the evolution of the wireless infrastructure, it is imperative to measure public's exposure. Yearly monitoring measurements would allow an overview of the public's exposure budget, since nowadays, rapid deployment of new RF radiation sources take place. The information obtained by the exposure studies allows assessing public's exposure to $\mathrm{RF}$ radiation today and in the years to come, when future epidemiologic studies seek for information in assessing the historic exposure levels to which the public was commonly exposed. Unfortunately studies on human risk from long-term environmental RF radiation based on personal exposure monitoring 
do not exist to our knowledge. Given the lack of good historic $\mathrm{RF}$ radiation exposure information to date, it is imperative that better efforts be directed to periodic collection of RF radiation exposures in daily life for use in epidemiological studies of cancer as well as of neurological diseases and other adverse health effects attributed to RF radiation exposures.

\section{Acknowledgements}

The study was supported by grants from Mr Brian Stein, Cancer- och Allergifonden, Cancerhjälpen, and PandoraFoundation for Independent Research, Berlin, Germany. The authors express their thanks to Jolanta Karpowicz in regard to exposimeter discussion.

\section{References}

1. Baan R, Grosse Y, Lauby-Secretan B, El Ghissassi F, Bouvard V, Benbrahim-Tallaa L, Guha N, Islami F, Galichet L and Straif K; WHO International Agency for Research on Cancer Monograph Working Group: Carcinogenicity of radiofrequency electromagnetic fields. Lancet Oncol 12: 624-626, 2011.

2. IARC Monographs on the Evaluation of Carcinogenic Risks to Humans. Volume 102. Non-Ionizing Radiation, Part 2: Radiofrequency Electromagnetic Fields. International Agency for Research on Cancer: Lyon, France, 2013. Available online: http://monographs.iarc.fr/ENG/Monographs/vol102/mono102. pdf (accessed on 1 June 2016)

3. IARC Monographs on the Evaluation of Carcinogenic Risks to Humans. Volume 80. Non-Ionizing Radiation, Part I: Static and Extremely Low-Frequency (ELF) Electric and Magnetic Fields. IARC Press, Lyon, France, 2002. Available online: http://monographs.iarc.fr/ENG/Monographs/vol80/mono80.pdf (accessed on 1 June 2016)

4. Hardell L, Carlberg M and Hansson Mild K: Pooled analysis of two case-control studies on use of cellular and cordless telephones and the risk for malignant brain tumours diagnosed in 1997-2003. Int Arch Occup Environ Health 79: 630-639, 2006.

5. Hardell L, Carlberg M and Hansson Mild K: Pooled analysis of two case-control studies on the use of cellular and cordless telephones and the risk of benign brain tumours diagnosed during 1997-2003. Int J Oncol 28: 509-518, 2006.

6. Hardell L, Carlberg M and Hansson Mild K: Pooled analysis of case-control studies on malignant brain tumours and the use of mobile and cordless phones including living and deceased subjects. Int J Oncol 38: 1465-1474, 2011.

7. INTERPHONE Study Group: Brain tumour risk in relation to mobile telephone use: Results of the INTERPHONE international case-control study. Int J Epidemiol 39: 675-694, 2010.

8. INTERPHONE Study Group: Acoustic neuroma risk in relation to mobile telephone use: Results of the INTERPHONE international case-control study. Cancer Epidemiol 35: 453-464, 2011

9. Cardis E, Armstrong BK, Bowman JD, Giles GG, Hours M, Krewski D, McBride M, Parent ME, Sadetzki S, Woodward A, et al: Risk of brain tumours in relation to estimated RF dose from mobile phones: Results from five Interphone countries. Occup Environ Med 68: 631-640, 2011.

10. Hardell L, Carlberg M, Söderqvist F and Mild KH: Pooled analysis of case-control studies on acoustic neuroma diagnosed 1997-2003 and 2007-2009 and use of mobile and cordless phones. Int J Oncol 43: 1036-1044, 2013.

11. Hardell L, Carlberg M, Söderqvist F and Mild KH: Case-control study of the association between malignant brain tumours diagnosed between 2007 and 2009 and mobile and cordless phone use. Int J Oncol 43: 1833-1845, 2013.

12. Hardell L, Carlberg M and Hansson Mild K: Use of mobile phones and cordless phones is associated with increased risk for glioma and acoustic neuroma. Pathophysiology 20: 85-110, 2013 .

13. Hardell L and Carlberg M: Mobile phone and cordless phone use and the risk for glioma - Analysis of pooled case-control studies in Sweden, 1997-2003 and 2007-2009. Pathophysiology 22: $1-13,2015$
14. Coureau G, Bouvier G, Lebailly P, Fabbro-Peray P, Gruber A, Leffondre K, Guillamo JS, Loiseau H, Mathoulin-Pélissier S, Salamon R, et al: Mobile phone use and brain tumours in the CERENAT case-control study. Occup Environ Med 71: 514-522, 2014.

15. Lerchl A, Klose M, Grote K, Wilhelm AF, Spathmann O, Fiedler T, Streckert J, Hansen V and Clemens M: Tumor promotion by exposure to radiofrequency electromagnetic fields below exposure limits for humans. Biochem Biophys Res Commun 459: 585-590, 2015.

16. Tillmann T, Ernst H, Streckert J, Zhou Y, Taugner F, Hansen V and Dasenbrock C: Indication of cocarcinogenic potential of chronic UMTS-modulated radiofrequency exposure in an ethylnitrosourea mouse model. Int J Radiat Biol 86: 529-541, 2010.

17. Repacholi MH, Basten A, Gebski V, Noonan D, Finnie J and Harris AW: Lymphomas in E mu-Piml transgenic mice exposed to pulsed $900 \mathrm{MHZ}$ electromagnetic fields. Radiat Res 147: 631-640, 1997.

18. Wyde M, Cesta M, Blystone C, Elmore S, Foster P, Hooth M, Kissling G, Malarkey D, Sills R, Stout M, et al: Report of Partial Findings from the National Toxicology Program Carcinogenesis Studies of Cell Phone Radiofrequency Radiation in Hsd: Sprague Dawley® SD rats (Whole Body Exposures). Draft 5-19-2016. US National Toxicology Program (NTP), 2016. doi: http://dx.doi.org/ http://dx.doi.org/10.1101/055699. Available online: http://biorxiv. org/content/biorxiv/early/2016/05/26/055699.full.pdf (accessed on 1 June 2016).

19. Khurana VG, Hardell L, Everaert J, Bortkiewicz A, Carlberg M and Ahonen M: Epidemiological evidence for a health risk from mobile phone base stations. Int J Occup Environ Health 16: 263-267, 2010.

20. International Commission on Non-Ionizing Radiation Protection: Guidelines for limiting exposure to time-varying electric, magnetic, and electromagnetic fields (up to $300 \mathrm{GHz}$ ). Health Phys 74: 494-522, 1998.

21. International Commission on Non-Ionizing Radiation Protection: ICNIRP statement on the 'Guidelines for limiting exposure to time-varying electric, magnetic, and electromagnetic fields (up

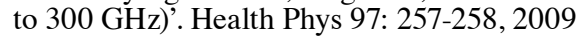

22. International Commission on Non-Ionizing Radiation Protection: General approach to protection against non-ionizing radiation. Health Phys 82: 540-548, 2002.

23. Gandhi OP, Morgan LL, de Salles AA, Han YY, Herberman RB and Davis DL: Exposure limits: The underestimation of absorbed cell phone radiation, especially in children. Electromagn Biol Med 31: 34-51, 2012

24. Hedendahl L, Carlberg M and Hardell L: Electromagnetic hypersensitivity - an increasing challenge to the medical profession. Rev Environ Health 30: 209-215, 2015.

25. BioInitiative Working Group: BioInitiative Report: A Rationale for a Biologically-based Public Exposure Standard for Electromagnetic Fields (ELF and RF). Sage C and Carpenter DO (eds.). Bioinitiative, 2007. Available online: http://www.bioinitiative.org/table-of-contents/ (accessed on 1 June 2016).

26. BioInitiative Working Group: BioInitiative 2012. A Rationale for a Biologically-based Public Exposure Standard for Electromagnetic Fields (ELF and RF). Sage C and Carpenter DO (eds.). Bioinitiative, 2012. Available online: http://www.bioinitiative.org/table-of-contents/ (accessed on 1 June 2016).

27. Thomas S, Kühnlein A, Heinrich S, Praml G, Nowak D, von Kries R and Radon K: Personal exposure to mobile phone frequencies and well-being in adults: A cross-sectional study based on dosimetry. Bioelectromagnetics 29: 463-470, 2008.

28. Thomas S, Heinrich S, von Kries R and Radon K: Exposure to radio-frequency electromagnetic fields and behavioural problems in Bavarian children and adolescents. Eur J Epidemiol 25: 135-141, 2010.

29. Heinrich S, Thomas S, Heumann C, von Kries R and Radon K: Association between exposure to radiofrequency electromagnetic fields assessed by dosimetry and acute symptoms in children and adolescents: A population based cross-sectional study. Environ Health 9: 75, 2010.

30. Buchner $\mathrm{K}$ and Eger $\mathrm{H}$ : Changes of clinically important neurotransmitters under the influence of modulated RF fields: A long-term study under real-life conditions. Umwelt-MedizinGesellschaft 24: 44-57, 2011 (In German).

31. Estenberg $\mathbf{J}$ and Augustsson T: Extensive frequency selective measurements of radiofrequency fields in outdoor environments performed with a novel mobile monitoring system. Bioelectromagnetics 35: 227-230, 2014. 
32. Gryz K, Karpowicz J, Leszko W and Zradziński P: Evaluation of exposure to electromagnetic radiofrequency radiation in the indoor workplace accessible to the public by the use of frequencyselective exposimeters. Int J Occup Med Environ Health 27: 1043-1054, 2014.

33. Gryz K and Karpowicz J: Radiofrequency electromagnetic radiation exposure inside the metro tube infrastructure in Warszawa. Electromagn Biol Med 34: 265-273, 2015.

34. Bolte JF and Eikelboom T: Personal radiofrequency electromagnetic field measurements in The Netherlands: Exposure level and variability for everyday activities, times of day and types of area. Environ Int 48: 133-142, 2012.

35. Hamnerius $\mathrm{Y}$ and Uddmar T: Microwave exposure from mobile phones and base stations in Sweden. Proceedings of the International Conference on Cell Tower Sitting 52-63, 2000. Available online: https://www.salzburg.gv.at/gesundheit_/ Documents/proceedings_(08)_hamnerius.pdf (accessed on 1 June 2016)

36. Foster KR: Radiofrequency exposure from wireless LANs utilizing Wi-Fi technology. Health Phys 92: 280-289, 2007.

37. Bhatt CR, Thielens A, Redmayne M, Abramson MJ, Billah B, Sim MR, Vermeulen R, Martens L, Joseph W and Benke G: Measuring personal exposure from $900 \mathrm{MHz}$ mobile phone base stations in Australia and Belgium using a novel personal distributed exposimeter. Environ Int 92-93: 388-397, 2016.

38. Bolte JF, Maslanyj M, Addison D, Mee T, Kamer J and Colussi L: Do car-mounted mobile measurements used for radio-frequency spectrum regulation have an application for exposure assessments in epidemiological studies? Environ Int 86: 75-83, 2016.

39. Eberhardt JL, Persson BR, Brun AE, Salford LG and Malmgren LO: Blood-brain barrier permeability and nerve cell damage in rat brain 14 and 28 days after exposure to microwaves from GSM mobile phones. Electromagn Biol Med 27: 215-229, 2008.

40. Salford LG, Brun AE, Eberhardt JL, Malmgren L and Persson BR: Nerve cell damage in mammalian brain after exposure to microwaves from GSM mobile phones. Environ Health Perspect 111: 881-883, discussion A408, 2003.

41. Nittby H, Brun A, Eberhardt J, Malmgren L, Persson BR and Salford LG: Increased blood-brain barrier permeability in mammalian brain 7 days after exposure to the radiation from a GSM-900 mobile phone. Pathophysiology16: 103-112, 2009.

42. Sirav B and Seyhan N: Effects of GSM modulated radio-frequency electromagnetic radiation on permeability of blood-brain barrier in male \& female rats. J Chem Neuroanat: Dec 23, 2015. pii: S0891-0618(15)00106-4. doi: 10.1016/j.jchemneu.2015.12.010. (Epub ahead of print).

43. Tang J, Zhang Y, Yang L, Chen Q, Tan L, Zuo S, Feng H, Chen Z and Zhu G: Exposure to $900 \mathrm{MHz}$ electromagnetic fields activates the mkp-1/ERK pathway and causes blood-brain barrier damage and cognitive impairment in rats. Brain Res 1601: 92-101, 2015.

44. Nittby H, Grafström G, Tian DP, Malmgren L, Brun A, Persson BR, Salford LG and Eberhardt J: Cognitive impairment in rats after long-term exposure to GSM-900 mobile phone radiation. Bioelectromagnetics 29: 219-232, 2008.

45. Grafström G, Nittby H, Brun A, Malmgren L, Persson BR Salford LG and Eberhardt J: Histopathological examinations of rat brains after long-term exposure to GSM-900 mobile phone radiation. Brain Res Bull 77: 257-263, 2008.

46. Gerner C, Haudek V, Schandl U, Bayer E, Gundacker N, Hutter HP and Mosgoeller W: Increased protein synthesis by cells exposed to a $1,800-\mathrm{MHz}$ radio-frequency mobile phone electromagnetic field, detected by proteome profiling. Int Arch Occup Environ Health 83: 691-702, 2010.

47. Markovà E, Malmgren LO and Belyaev IY: Microwaves from mobile phones inhibit 53BP1 focus formation in human stem cells more strongly than in differentiated cells: Possible mechanistic link to cancer risk. Environ Health Perspect 118: 394-399, 2010.

48. Fragopoulou AF, Samara A, Antonelou MH, Xanthopoulou A, Papadopoulou A, Vougas K, Koutsogiannopoulou E, Anastasiadou E, Stravopodis DJ, Tsangaris GT, et al: Brain proteome response following whole body exposure of mice to mobile phone or wireless DECT base radiation. Electromagn Biol Med 31: 250-274, 2012.

49. Dasdag S, Akdag MZ, Erdal ME, Erdal N, Ay OI, Ay ME, Yilmaz SG, Tasdelen B and Yegin K: Effects of $2.4 \mathrm{GHz}$ radiofrequency radiation emitted from Wi-Fi equipment on microRNA expression in brain tissue. Int J Radiat Biol 91: 555-561, 2015.
50. Dasdag S, Taş M, Akdag MZ and Yegin K: Effect of long-term exposure of $2.4 \mathrm{GHz}$ radiofrequency radiation emitted from Wi-Fi equipment on testes functions. Electromagn Biol Med 34: 37-42, 2015.

51. Avendaño C, Mata A, Sanchez Sarmiento CA and Doncel GF Use of laptop computers connected to internet through Wi-Fi decreases human sperm motility and increases sperm DNA fragmentation. Fertil Steril 97: 39-45.e2, 2012.

52. Atasoy HI, Gunal MY, Atasoy P, Elgun S and Bugdayci G: Immunohistopathologic demonstration of deleterious effects on growing rat testes of radiofrequency waves emitted from conventional Wi-Fi devices. J Pediatr Urol 9: 223-229, 2013.

53. Akdag MZ, Dasdag S, Canturk F, Karabulut D, Caner Y and Adalier N: Does prolonged radiofrequency radiation emitted from $\mathrm{Wi}-\mathrm{Fi}$ devices induce DNA damage in various tissues of rats? J Chem Neuroanat: Jan 8, 2016. pii: S0891-0618(16)00005-3. doi: 10.1016/j.jchemneu.2016.01.003 (Epub ahead of print).

54. Yakymenko I, Tsybulin O, Sidorik E, Henshel D, Kyrylenko O and Kyrylenko S: Oxidative mechanisms of biological activity of low-intensity radiofrequency radiation. Electromagn Biol Med 19: 1-17, 2015.

55. Burlaka A, Tsybulin O, Sidorik E, Lukin S, Polishuk V, Tsehmistrenko S and Yakymenko I: Overproduction of free radical species in embryonal cells exposed to low intensity radiofrequency radiation. Exp Oncol 35: 219-225, 2013.

56. Megha K, Deshmukh PS, Banerjee BD, Tripathi AK and Abegaonkar MP: Microwave radiation induced oxidative stress, cognitive impairment and inflammation in brain of Fischer rats. Indian J Exp Biol 50: 889-896, 2012.

57. Megha K, Deshmukh PS, Banerjee BD, Tripathi AK, Ahmed R and Abegaonkar MP: Low intensity microwave radiation induced oxidative stress, inflammatory response and DNA damage in rat brain. Neurotoxicology 51: 158-165, 2015.

58. Deshmukh PS, Nasare N, Megha K, Banerjee BD, Ahmed RS, Singh D, Abegaonkar MP, Tripathi AK and Mediratta PK: Cognitive impairment and neurogenotoxic effects in rats exposed to low-intensity microwave radiation. Int J Toxicol 34: 284-290, 2015.

59. Megha K, Deshmukh PS, Ravi AK, Tripathi AK, Abegaonkar MP and Banerjee BD: Effect of low-intensity microwave radiation on monoamine neurotransmitters and their key regulating enzymes in rat brain. Cell Biochem Biophys 73: 93-100, 2015.

60. Deshmukh PS, Banerjee BD, Abegaonkar MP, Megha K, Ahmed RS, Tripathi AK and Mediratta PK: Effect of low level microwave radiation exposure on cognitive function and oxidative stress in rats. Indian J Biochem Biophys 50: 114-119, 2013.

61. Hardell L and Carlberg M: Using the Hill viewpoints from 1965 for evaluating strengths of evidence of the risk for brain tumors associated with use of mobile and cordless phones. Rev Environ Health 28: 97-106, 2013.

62. Urbinello D, Joseph W, Verloock L, Martens L and Röösli M: Temporal trends of radio-frequency electromagnetic field (RF-EMF) exposure in everyday environments across European cities. Environ Res 134: 134-142, 2014.

63. Frei P, Mohler E, Neubauer G, Theis G, Bürgi A, Fröhlich J, Braun-Fahrländer C, Bolte J, Egger M and Röösli M: Temporal and spatial variability of personal exposure to radio frequency electromagnetic fields. Environ Res 109: 779-785, 2009.

64. Bolte JF, van der Zande G and Kamer J: Calibration and uncertainties in personal exposure measurements of radiofrequency electromagnetic fields. Bioelectromagnetics 32: 652-663, 2011.

65. Rowley JT and Joyner KH: Comparative international analysis of radiof requency exposure surveys of mobile communication radio base stations. J Expo Sci Environ Epidemiol 22: 304-315, 2012.

66. Markakis I and Samaras T: Radiofrequency exposure in Greek indoor environments. Health Phys 104: 293-301, 2013.

67. Viel JF, Tiv M, Moissonnier M, Cardis E and Hours M: Variability of radiofrequency exposure across days of the week: A population-based study. Environ Res 111: 510-513, 2011.

68. Joseph W, Frei P, Roösli M, Thuróczy G, Gajsek P, Trcek T, Bolte J, Vermeeren G, Mohler E, Juhász P, et al: Comparison of personal radio frequency electromagnetic field exposure in different urban areas across Europe. Environ Res 110: 658-663, 2010.

69. Tell RA and Kavet R: A survey of the urban radiofrequency (RF) environment. Radiat Prot Dosimetry 162: 499-507, 2014. 